Funding: The study was funded by the Department of Gynaecology, University Medical Center Utrecht, and by the Research Institute for Psychology and Health.

Competing interests: None declared.

Ethical approval: The study was approved by the Medical Ethics Committee of the University Medical Center Utrecht

Jacobs S, Mazure C, Prigerson H. Diagnostic criteria for traumatic grief Death Stud 2000:24:185-99.

Stroebe W, Schut H. Risk factors in bereavement outcome: methodological and empirical review. In: Stroebe MS, Hansson RO, Stroebe W, Schut H, eds. Handbook of bereavement research. Washington DC: American Psychological Association, 2001:613-45.

3 Kelly BJ, Varghese FT. Assisted suicide and euthanasia: what about the clinical issues? Aust N Z J Psychiatry 1996;30:3-8.

Swarte NB, Heintz AP. Euthanasia and physician-assisted suicide. Ann Med 1999;31:364-71.

5 Pijnenborg L, Van Delden JJ, Kardaun JW, Glerum JJ, Van der Maas PJ. Nationwide study of decisions concerning the end of life in general practice in the Netherlands. BMJ 1994;309:1209-12.

6 Van der Maas PJ, Van der Wal G, Haverkate I, de Graaff CL, Kester JG, Onwuteaka-Philipsen BD, et al. Euthanasia, physician-assisted suicide and other medical practices involving the end of life in the Netherlands, 1990-1995. N Engl J Med 1996;335:1699-705.

7 Swarte NB, Heintz APM. Guidelines for an acceptable euthanasia procedure. Baillieres Clin Obstet Gynaecol 2000;15:313-21.

8 Boelen PA, Van den Bout J, de Keijser J, Hoijtink H. Reliability and validity of the Dutch version of the inventory of traumatic grief (ITG). Death Stud 2003;27:1-21

9 Faschingbauer RRZS, DeVaul R. The Texas revised inventory of grief. In Zisook S, ed. Biopsychosocial aspects of bereavement. Washington DC: American Psychiatric Press, 1987:127-38.
10 Horowitz MJ, Wilner N, Alvarez W. Impact of event scale: a measure of subjective stress. Psychosom Med 1979;41:209-18.

11 Arrindell WA, Ettema J. SCL-90. Manual for a multidimensional indicator of psychopathology. Lisse: Swets and Zeitlinger, 1986.

2 Lubin B. Adjective checklist for measurement of depression. Arch Gen Psychiatry 1965;12:57-62

13 Wegner M, Schwarzer R, Jerusalem M. Generalized self-efficacy. In Schwarzer R, ed. Measurement of perceived self-efficacy. Psychometric Scales for cross-cultural research. Berlin: Freie Universität Berlin, 1993.

4 Sanderman R, Arrindell WA, Ranchor AV, Eysenck HJ. Eysenck personality questionnaire. Groningen, University of Groningen, 1995.

15 Van den Boom F. AIDS, euthanasia and grief. AIDS Care 1995;7(suppl 2):S175-85

16 Groenewoud JH, Van der Heide A, Onwuteaka-Philipsen BD, Willems DL, Van der Maas PJ, Van der Wal G. Clinical problems with the performance of euthanasia and physician-assisted suicide in the Netherperformance of euthanasia and physicia
lands. N Engl J Med 2000;342:551-6.

17 Emanuel EJ. Euthanasia and physician-assisted suicide. Arch Intern Med 2002;162:142-52.

18 Stroebe MS, Stroebe W. Who participates in bereavement research? A review and empirical study. Omega 1989;20:1-29.

19 Van der Wal G, Dillmann RJ. Euthanasia in the Netherlands. BMJ 1994;308:1346-9.

20 Chochinov HM, Tataryn DJ, Wilson KG, Ennis M, Lander S. Prognostic awareness and the terminally ill. Psychosomatics 2000;41:500-4.

21 Valdimarsdottir U, Helgason AR, Furst CJ, Adolfsson J, Steineck G. The unrecognised cost of cancer patients' unrelieved symptoms: a nationwide follow-up of their surviving partners. Br J Cancer 2002; 86:1540-5.

22 BrintzenhofeSzoc KM, Smith ED, Zabora JR. Screening to predict complicated grief in spouses of cancer patients. Cancer Prac 1999;7:233-9.

23 Koop PM, Strang V. Predictors of bereavement outcomes in families of patients with cancer: a literature review. Can J Nurs Res 1997;29:33-50. (Accepted 17 June 2003)

\title{
A good death in Uganda: survey of needs for palliative care for terminally ill people in urban areas
}

\author{
Ekiria Kikule
}

Hospice Africa (Uganda), PO Box 7757 , Kampala,

Uganda

Ekiria Kikule

executive director

ekikule@

hospiceafrica.or.ug

BMJ 2003;327:192-4

\author{
Abstract \\ Objective To identify the palliative care needs of \\ terminally ill people in Uganda. \\ Design Descriptive cross sectional study. \\ Setting Home care programmes in and around \\ Kampala that look after terminally ill people in their \\ homes.
}

Participants 173 terminally ill patients registered with the home care programmes.

Results Most of the participants had either

HIV/AIDS or cancer or both; 145 were aged under 50 years, and 107 were women. Three main needs were identified: the control or relief of pain and other symptoms; counselling; and financial assistance for basic needs such as food, shelter, and school fees for their children. The preferred site of care was the home, though all these people lived in urban areas with access to healthcare services within $5 \mathrm{~km}$ of their homes.

Conclusion A "good death" in a developing country occurs when the dying person is being cared for at home, is free from pain or other distressing symptoms, feels no stigma, is at peace, and has their basic needs met without feeling dependent on others.

\section{Introduction}

The epidemic of HIV/AIDS has stretched the already poorly resourced healthcare infrastructure in subSaharan Africa, including Uganda. Access to basic health care is limited to only $41 \%$ of the population. Annual expenditure per capita stands at just $\$ 12$ (€10, $£ 7$ ), and $34 \%$ of the population live in absolute poverty (living on or earning less than $\$ 1$ a day and unable to afford enough food to consume 2000 to 3000 calories a day). ${ }^{1}$

Nearly all terminally ill patients die in their own homes under the care of their families, having been discharged from hospital as their diseases have no cure. Little is known about the care they receive or how they die. Palliative care, especially end of life care, is still new in Uganda. It was introduced in 1993 by Hospice Africa (Uganda). There is overwhelming demand for care for the dying but inadequate funding. I carried out this study to identify the palliative care needs of those dying at home in an attempt to improve their quality of life up to the time they die. Participants were drawn from home care programmes in and around Kampala. These programmes were started by non-governmental health services to help in the home care of bedridden people with HIV/AIDS and cancer.

\section{Methods}

This descriptive cross sectional study was carried out from January to April 2000 in Kampala district. The study population included all 320 people who were terminally ill with either cancer or HIV/AIDS, or both, and were bedridden at home and registered with any one of the home care programmes in Kampala. Using the formula for simple random sampling for single 


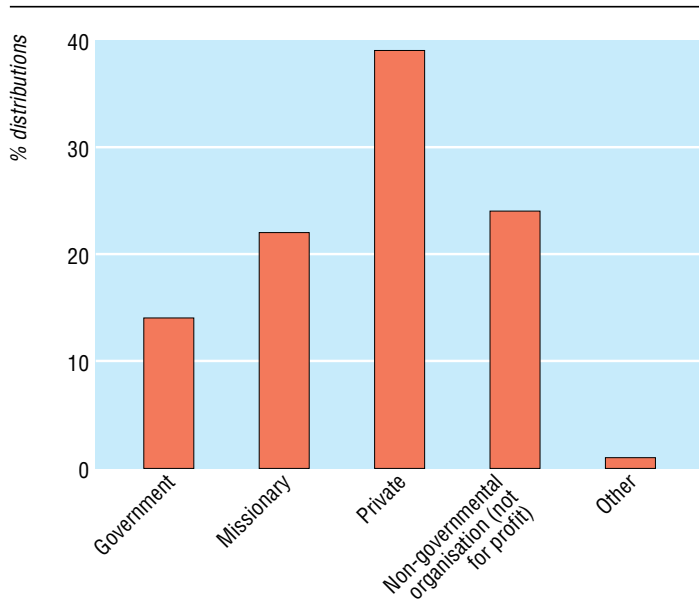

Fig 1 Healthcare facilities used by terminally ill patients in Uganda

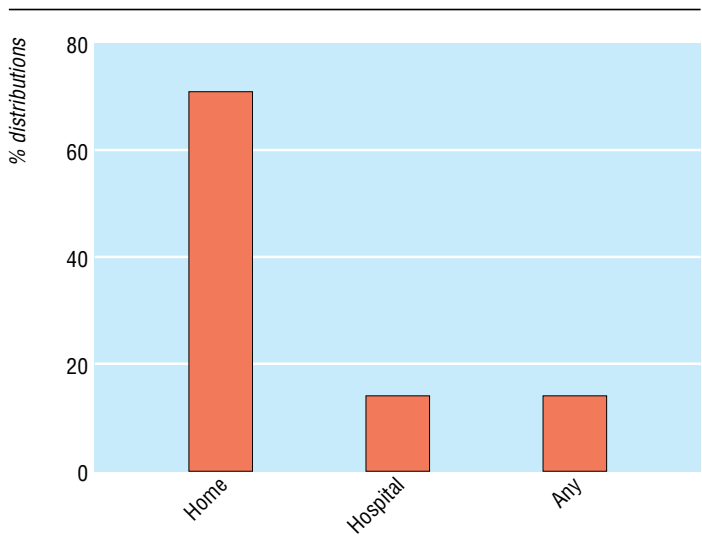

Fig 2 Where terminally ill patients in Uganda prefer to be cared for

proportions of Kish, ${ }^{2}$ I calculated that I needed a sample size of 170 . I selected study participants from programme registers using random numbers generated by computer. More participants than the sample size were selected in case a selected participant either did not want to participate in the study or died before data could be collected.

I explained the study objectives to the home care programme managers and counsellors in each programme and collected data from the participants after the objectives of the study were explained to them and verbal consent obtained. Patients were assured that any information would be treated in confidence and that they would still receive care from the programme even if they did not want to participate in the study.

I developed a questionnaire and field tested it among patients registered in one of the home care programmes. This programme did not take part in the actual study. Six research assistants, who were counsellors in the home care programmes, were trained to use the pretested standardised questionnaire, both in English and Luganda, the local language commonly spoken around Kampala. They covered the whole district, tracing the selected participants in their homes and administering the questionnaire. Quantitative data were entered, cleaned, and analysed with EpiInfo 6.0.

\section{Results}

A total of 173 patients were interviewed, of whom 145 $(84 \%)$ were under 50 years of age and $107(62 \%)$ were women. Almost all the participants in the study $(98 \%$, $170)$ knew their diagnoses: HIV/AIDS (73\%), cancer $(22 \%)$, both (3\%), and other conditions $(2 \%)$.

\section{Healthcare facilities}

About three quarters $(73 \%, 127)$ of the interviewed participants lived within $5 \mathrm{~km}$ of the nearest health facility compared with $55 \%$ of the general Uganda population. ${ }^{3}$ Only 14\% (24) used the government health facilities (with free health services) near their homes (fig 1).

During the course of their illness 67\% (116) of participants used only "Western medications," 35\% (56) used both Western and traditional herbal medications, while $1 \%$ (2) used herbs exclusively. In similar studies in two rural districts of Uganda, participants described consulting traditional healers as one of the family's first coping mechanisms when facing a terminal illness (unpublished data).

\section{Needs and problems}

Despite such access to health facilities, terminally ill patients at home still had unmet needs. The 173 participants identified 235 needs. Pain and other symptoms such as vomiting and diarrhoea were cited as the main problem by $58 \%$ (136). In $30 \%$ of cases (71) the participants had lost all income due to illness, resulting in acute financial needs. Counselling was needed which was said to heal family relationships and to facilitate funeral arrangements.

The home was the preferred site for care (fig 2), the reasons for which included: "It is cheaper for me as there are no transport costs involved," "At home I feel safe and I am surrounded by my family," and "I have my privacy and it is convenient for those who want to visit me."

\section{Discussion}

In 1990, the World Health Organization estimated that over 5 million people worldwide were experiencing cancer pain every day and called cancer pain a "major public health problem." Most such cases are in developing countries like Uganda, where drugs to

\section{Needs and problems identified among terminally ill people in} Uganda

$\begin{array}{ll}\text { Problems (\% reporting problem) } & \text { Needs } \\ \text { Pain and other symptoms (58\%) } & \text { Pain relief, control of other symptoms } \\ \text { Loss of income (30\%) } & \begin{array}{l}\text { Financial help } \\ \text { - Rent/food/school fees }\end{array} \\ & \text { - Purchase of drugs } \\ \text { - Good feeding } & \text { Counselling } \\ \text { Broken marriages (5\%) } & \text { - Funeral arrangements } \\ & \text { - Reduce stigmatisation } \\ & \begin{array}{l}\text { Return to work, involvement in } \\ \text { decision making }\end{array} \\ \text { Dependency }(6 \%) & \text { Spiritual/legal help, company, etc }\end{array}$


control such pain are not readily available. ${ }^{4}$ Indeed, in this study over half of the participants' identified needs $(136 / 235)$ stated pain as the chief problem. This is consistent with the findings of Murray and colleagues in a study in Meru, Kenya. They found that physical pain dominated the lives of Kenyan patients and their carers. $^{5}$

Participants in this study also described the need for counselling, both for themselves and their families, because they felt stigmatised, dependent, and abandoned. Terminally ill people felt dependent on their families for physical care, finances, and decision making. Furthermore, fear, prejudice, and a lack of compassion from others left many patients and families feeling isolated. ${ }^{6}$

Loss of income was a problem for nearly a third of participants. This probably resulted in a family crisis if it was the head of the household who was terminally ill. Participants needed money not only for medical care but also for basic needs such as food, rent, and school fees for their children. Indeed, the Ugandan government has estimated that $42 \%$ of the total monthly household expenditure in urban areas goes to buy food. Lack of food, therefore, is an important indicator of household poverty. ${ }^{7}$

Participants preferred home as the site of care. The reasons given included minimising costs (it is cheaper to be at home), wanting to be surrounded by their families, believing the care received at home through the home care programmes was adequate, and privacy. From the perspectives of these patients, the home was a safe place in which to suffer, not just a building. It also houses the relationship between patient and family. This relationship should enable the patient to feel safe to express their distress as this in itself is therapeutic. ${ }^{8}$

Few patients with terminal illnesses go to government health facilities because such facilities are generally poorly equipped and the health staff, burdened with dealing with other curable conditions, do not have time for terminally ill people.

\section{Limitations}

This study is limited in that it examined the patients' needs at the time of the study but does not indicate whether these needs changed as death approached. The study also indicates places that patients and families prefer for care but does not explicitly examine the issue of preferred place for death. More studies are underway at Hospice Africa (Uganda) to establish whether the home is still the preferred site for death for both the patient and the family. This study did not differentiate between patients with HIV/AIDS and those with cancer. Nevertheless, in Uganda the two conditions are closely related because of the emergence of cancers associated with AIDS. Most participants were aged between 21 and 50 years. This agrees with other studies done in Uganda, which showed that AIDS predominantly affects people in the most productive period of their lives. ${ }^{9}$ In Uganda, $70 \%$ of the people living with HIV/AIDS are aged 15-45 years. ${ }^{10}$

\section{Conclusion}

In Uganda a "good death" occurs at home, in the absence of pain and other distressing symptoms, without stigma or a sense of dependence, and with adequate finances for the basic needs.

\section{What is already known on this topic}

The HIV/AIDS epidemic has compounded poverty as well as paucity of heathcare services in sub-Saharan Africa

The family has borne the brunt of terminal illness in its midst and the home is the site of care for many with incurable illnesses

\section{What this study adds}

Terminally ill people in Uganda want to die at home, without pain, stigma, or a sense of dependence

Many terminally ill people express a need for counselling, and experience financial hardship

This paper is from a study done as part of the requirements for a masters degree in public health at Makerere University. The full report of the study is available at Hospice Africa (Uganda), Kampala.

Contributors: Alexander Bogere, Christine Nabulya, Resty Ndagano, Christine Namutebi, Gailey Turyahebwa, and Fred Khisa collected the data. Albert Maganda analysed the results. EK designed the research tool, wrote the research report, and is guarantor.

Funding: INCLEN Grant (Palliative Care) through Makerere University. The guarantor accepts full responsibility for the conduct of the study, had access to the data, and controlled the decision to publish.

Competing interests: EK is currently executive director of Hospice Africa (Uganda). When the study was designed and carried out EK had no personal interest in the organisation's activities.

Ethical approval: Permission to conduct the study was obtained from the Kampala District Director of Health Services and from each of the home care programme managers.

1 Okuonzi SA. HSSP mid-term review: Are we achieving strategic outputs or are we lost in trivialities and details of process? Uganda Health Bulletin. A Journal on Health Policy and Systems Development. 2003;9:Jan-March.

2 Kish L. Survey sampling. New York: John Wiley, 1965.

3 United Nations Development Programme. Uganda human development report. New York: UNDP, 2000.

4 Cancer pain relief and palliative care. Report of a WHO expert committee. World Health Organ Tech Rep Ser 1990;804:1-75.

5 Murray SM, Grant E, Grant A, Kendall M. Dying from cancer in developed and developing countries: lessons from two qualitative developed and developing countries: lessons from two qu
interview studies of patients and their carer. BMJ 2003;326:368.

6 Sims R, Moss V. Terminal care for people with AIDS. London: Hodder \& Stoughton, 1995:1-4

Ministry of Finance, Planning and Economic Development (MoFPED). Poverty status report. Kampala, Uganda: MoFPED, 1999:10-21, 114-131.

Regnard FBC, Tempest S. A guide to symptom relief in advanced disease. 4th ed. Cheshire: Hochland \& Hochland, 1998.

Katabira E, Mubiru F, Van Praag E. Care for people living with HIV/AIDS. World Health 1998; No 6:16-7.

10 UNAIDS/WHO. AIDS epidemic update. Geneva: UNAIDS/WHO, 1998:1-3.

(Accepted 6 June 2003)

\section{Endpiece}

\section{Inside our dreams}

Where do people go to when they die? Somewhere down below or in the sky? 'I can't be sure,' said Grandad, 'but it seems They simply set up home inside our dreams.' Jeanne Willis 